\title{
O CRIME DE VIOLÊNCIA DOMÉSTICA: REFLEXÃO A \\ PROPÓSITO DO CRIME COMETIDO SOB A FORMA \\ DE OMISSÃO E O CONCURSO COM O CRIME \\ DE OMISSÃO DE AUXÍLIO*
}

\author{
Alexandra Vilela*
}

\begin{abstract}
SUMÁRIO: 1. Introdução; 2. Algumas considerações genéricas sobre o crime de violência doméstica; 3 . O crime de violência doméstica cometido sob a forma omissiva; 4 . Relações de concurso entre o crime de violência doméstica e o crime de omissão de auxílio; 5 . Conclusão.
\end{abstract}

RESUMO: No presente artigo, é levada a cabo uma breve análise acerca do crime de violência doméstica, onde se inclui a referência à possibilidade de ele ser praticado sob a forma de omissão impura. Para tanto, analisam-se as possíveis fontes do dever de garante, os seus eventuais titulares, bem como as hipotéticas situações em que tal crime omissivo poderá surgir. Em seguida, é analisada uma hipótese académica a fim de averiguar as diferentes relações de concurso que este crime poderá, eventualmente, manter com o crime de omissão de auxílio.

Palavras-Chave: Violência doméstica, mau trato, dever de garante; omissão impura, omissão de auxílio; cônjuge; família, pessoa particularmente indefesa.

Abstract: This article will briefly analyze the crime of domestic violence, including the possibility of being committed as in impure omission. In this way, the possible sources of the duty of guarantor and eventual holders are analyzed, as what are the hypothetical situations in which such crime of omission may arise. Then, an academic case provides the analysis to find out the different concurrence regarding this crime and if it's eventually connected to the crime of omission of assistance.

\footnotetext{
* O presente corresponde à versão desenvolvida e aprofundada da Conferência que apresentámos no âmbito do Colóquio Violência Doméstica: uma abordagem interdisciplinar, que decorreu no 2 de Dezembro de 2020, na Universidade Lusófona de Humanidades e Tecnologia, organizado pela respectiva Faculdade de Direito. Note-se, no entanto, que o respectivo título foi alterado. Por opção da autora, o presente artigo não segue o Acordo Ortográfico de 1990.

** Doutora em Direito pela Faculdade de Direito de Coimbra, Professora Associada da Faculdade de Direito da ULP e da ULHT, Membro do CIDPCC e do CEAD.
} 
KeYwords: Domestic violence, physical abuse, duty of guarantor; impure omission, omission of assistance; spouse; family, particularly defenceless person. 


\section{INTRODUÇÃo}

Não pensamos que seja tarefa fácil reflectir sobre o crime de violência doméstica cometido sob a forma de omissão impura e, em seguida, configurar casos em que aquele crime possa entrar em concurso efectivo ou verdadeiro com o da omissão de auxílio, previsto no artigo $2000^{\circ}$ do CP. Não obstante, abalançamo-nos nessa tarefa, porque entendemos que o presente crime, dado o seu aumento exponencial e a sua cada vez maior relevância, merece ser estudado de um modo aprofundado, aqui se incluindo, obviamente, a questão em apreço. Por assim ser, este artigo representa tão-somente uma ínfima parte dessa reflexão, mas também e apenas o seu início.

Diremos, pois, que o crime de violência doméstica, actualmente previsto no artigo $152 .^{\circ}$ do $\mathrm{CP}$, apresenta-se como um crime que pode ser cometido através de diferentes modalidades de conduta e que o seu número 1 possui uma formulação que deixa em aberto outras formas de cometer os maus-tratos que aqui relevam. A estes factos, susceptíveis de dificultarem o estudo em causa, acresce aqueloutro de este crime ter sido construído, aquando da revisão de 2007 ao CP, a partir do de maus-tratos, opção cuja bondade se nos afigura de duvidoso acerto há já algum tempo ${ }^{1}$.

De qualquer modo, na reflexão que iremos desenvolver, centrar-nos-emos, essencialmente, sobre os casos em que o agente é o autor da violência doméstica e, simultaneamente, o omitente. Razão pela qual os casos em que, depois de um agente praticar o crime de violência doméstica, um terceiro omite uma acção salvadora do bem jurídico em causa serão objecto apenas de uma pequena referência.

Estabeleçamos, pois, um roteiro do nosso estudo e que se inicia, precisamente, com algumas considerações genéricas, às quais se seguirá a indicação das nossas dúvidas quanto ao bem jurídico protegido, bem como a referência a alguns dos elementos do tipo objectivo, a sua classificação, não só quanto ao modo de ofensa, como também quanto à conduta do agente.

1 Foi clara a intenção do legislador de enveredar por esse caminho, sendo que ela foi assumida na Exposição de Motivos da então Proposta de Lei n. ${ }^{\circ}$ 98/X. Com efeito, aí se diz que "[a]inda em sede de crimes contra a integridade física, os maus-tratos, a violência doméstica e a infracção de regras de segurança passam a ser tipificadas em preceitos distintos, em homenagem às variações de bem jurídico protegido". Também não obliteramos que foi, outrossim, objectivo deste legislador, o alargamento "do âmbito subjectivo do crime". Cf. a "Exposição de Motivos" da Proposta de Lei n. ${ }^{\circ}$ 98/X, pp. 8-9. 
Sem este percurso, consideramos que não é possível reflectir sobre o tema aqui convocado.

\section{Algumas consideraçóes genéricas sobre o Crime de VIOLÊNCIA DOMÉSTICA}

O crime do artigo $152 .^{\circ}$ é composto por um tipo legal fundamental, que é o de violência doméstica simples, previsto no número 1; o do número 2 , qualificado em função de uma ilicitude mais grave do que a do tipo de ilícito fundamental previsto no número 1 e, por fim, o do número 3, caso típico de um crime preterintencional, em que o crime fundamental doloso é o de violência doméstica, e o evento agravante é a morte ou uma ofensa à integridade física grave ${ }^{2}$.

Levando em consideração o número 1 do artigo $152 .^{\circ}$, onde se encontra previsto o tipo de violência doméstica simples, importa considerar que, de acordo com a sua parte final, por razões de subsidiariedade, esse mesmo crime de violência doméstica simples é afastado pelos crimes que sejam puníveis com pena de prisão superior a cinco anos. Vale por dizer: o tipo legal previsto no número 1 é afastado pelo crime de ofensas à integridade física grave, bem como pelos crimes contra a liberdade pessoal que sejam punidos com pena superior àquela acabada de referir. Mas já não o será, quando nos movemos no âmbito do crime de violência doméstica qualificado ou agravado pelo resultado, respectivamente previstos nos números 2 e 3 do artigo $152 .^{\circ}$. Com efeito, de acordo com uma correcta interpretação da norma

2 Um outro nódulo problemático que importa referir prende-se, ainda, com a expressão modo reiterado, usada logo no crime fundamental de violência doméstica, contida no número 1 do artigo $152 .^{\circ}$ e, assim, a discutir se uma agressão isolada é suficiente para se dar como presente tal crime. Por certo que o será se essa dimensão que identificámos provisoriamente como o respeito familiar, ou substancialmente análogo a este, for atingido. No que diz respeito a este ponto, cf., por um lado, Taipa de Carvalho e, do outro, Paulo Pinto De Albuquerque. O primeiro defende, em síntese conclusiva, que "uma acção isolada de pouca gravidade, mesmo que in se configure uma infracção criminal (p. ex., uma leve ofensa corporal ou injúria) não deve ser qualificada como um crime (grave...) de violência doméstica ou de maus-tratos". Cf. do autor, "Art. 152.", pp. 517 e ss. e, em especial, p. 519, in: Comentário Conimbricense ao Código Penal, (2. a edição, Org. Figueiredo Dias, Coimbra: Coimbra Editora, 2012), 512. Por sua vez, Paulo Pinto de Albuquerque escreve abertamente que os maus-tratos podem ser reiterados ou não. Cf., do autor, Comentário do Código Penal Português à luz da Constituição da República e da Convenção Europeia dos Direitos do Homem, (3. ${ }^{a}$ edição actualizada, Lisboa: Universidade Católica Editora, 2015), 593. 
jurídica incriminatória, atendendo à localização da regra da subsidiariedade, na parte final do número 1 do artigo 152. ${ }^{\circ}$, não nos parece defensável afirmar que tal regra se aplica ao delito qualificado e ao agravado.

No que ao bem jurídico protegido em sede deste crime diz respeito, importa esclarecer que o legislador português inseriu-o no âmbito dos crimes contra a integridade física, embora tenha ressalvado que a violência doméstica passou a ser tipificada "em preceitos distintos, em homenagem às variações de bem jurídico protegido" 3 . Deste modo, e pese embora termos dúvidas de que uma fundada reflexão sobre a definição do bem jurídico tenha estado na preocupação do legislador penal português, entendemos, apoiados em Taipa de Carvalho, que ele não se resume nem à integridade física ou psíquica, nem à liberdade, nem à honra, ficando assim definitivamente encerrada a possibilidade de o considerar como um crime que apenas protege a integridade física da vítima ${ }^{4}$.

É certo que anteriormente acompanhamos Taipa de Carvalho quando referiu que o bem jurídico protegido pelo crime de violência doméstica seria um "bem jurídico complexo que abrange a saúde física, psíquica e mental", que, em última análise, visaria a "protecção da pessoa individual e da sua dignidade humana"s. No entanto, ao presente momento, não conseguiríamos ser tão peremptórios em tal afirmação ${ }^{6}$, cientes, outrossim, de que o bem jurídico protegido também não é a comunidade familiar ou conjugal, porquanto o bem jurídico tem de ser necessariamente pessoal e não supra-individual ${ }^{7}$. Não. O bem jurídico deverá ser mais denso, envolto, por assim

3 Cf. a "Exposição de Motivos" da Proposta de Lei n. ${ }^{\circ}$ 98/X, pp. 8-9.

4 Com efeito, diz-nos o autor em texto referido que, outrora, considerava-se que o bem jurídico era apenas a integridade física, sendo o crime de maus-tratos uma forma qualificada ou agravada do crime de ofensas à integridade física, actualmente, um tal entendimento é de excluir. Cf. Taipa de Carvalho, "ART. 152.", 512.

\section{Ibidem.}

6 Em texto, estamos a referir-nos ao que escrevemos em Janeiro de 2019, no nosso "A propósito do designado 'Direito Penal da Família”, in: Homenagem ao Professor Doutor Germano Marques da Silva, I, Coord.: José Lobo Moutinho et alli, (Lisboa: Universidade Católica Editora, 2020), 70-71.

7 Cf. Taipa de Carvalho, "Art. 152.", 512. E, no mesmo sentido, Nuno Brandão, «A tutela penal especial reforçada da violência doméstica", in: Julgar online, n. ${ }^{\circ} 12,2010,13$. Acrescenta, outrossim, que a dignidade humana também não é aqui especificamente protegida, porque transversal a todo o sistema jurídico, p. 14, do mesmo artigo. A este propósito, veja-se, ainda, Alexandra Vilela, "A propósito do designado 'Direito Penal da Família”", 71. 
dizer, em qualquer coisa mais que não o resuma aos bens atrás identificados. O que será então?

Iremos identificá-lo, mas apenas de uma forma provisória, pois que uma aturada reflexão, que não se compadece com a economia deste artigo, se impõe, como um pedaço de realidade que é o respeito pela vítima com quem se mantém uma relação familiar ou a ela análoga. Ou seja, este respeito está titulado na pessoa com quem o agente se relaciona dentro de casa ou no seio do lar (daí a expressão doméstica), seja essa relação sentimental ou familiar e que envolve um dever de protecção e de vigilância da vítima. Como se percebe, este respeito apenas poderá surgir nesse contexto relacional, não se confundindo, por conseguinte, nem com a honra, nem com a consideração que todas as pessoas merecem.

$\mathrm{Na}$ verdade, cremos que não é em vão que a epígrafe da norma é violência doméstica, sendo que o substantivo "doméstico" significa "que é relativo à família, à casa”. Não é em vão ainda que este crime, no ano de 2007 , se desprendeu do de maus-tratos, ganhando autonomia.

Consequentemente, o tipo legal de crime fica preenchido quando o agente inflija à vítima um mau trato físico ou psíquico, mau trato esse que não tem de ser necessariamente um dos descritos no tipo (aquela enumeração do número 1 é meramente exemplificativa), nem tem de ser uma ofensa psíquica ou típica que se encontre tipificada por outro tipo legal ${ }^{9}$. Todavia, esse mau trato deve, ainda, ser adequado a afectar o bem jurídico protegido e que identificaremos, então, como aquela dimensão do respeito, pedaço de realidade imaterial que apenas encontramos no seio de uma comunidade familiar, parafamiliar, motivo pelo qual não tem de ser uma ofensa à integridade física ou à liberdade.

Sob o ponto de vista dos tipos de tipicidade, e de acordo com o texto legal, e atendendo ao bem jurídico identificado pela doutrina maioritária, o legislador português edificou um crime de dano, mas que, por vezes, se apresenta como um crime de perigo ${ }^{10}$, como é o caso do crime de ameaças. Igualmente

8 Cf. Dicionário de Lingua Portuguesa Contemporânea, da Academia de Ciências de Lisboa, (Lisboa: Editorial Verbo, 2001), 1304.

9 Cf. Taipa de Carvalho, "Art. 152.", 514.

10 A propósito desta problemática, Nuno Brandão escreve que, no seu entendimento, "assume não a natureza de crime de dano, mas sim de crime de perigo, nomeadamente, de crime de perigo abstracto". Cf. do autor, "A tutela penal especial", 17. 
à luz da lei, trata-se de um tipo que tanto se pode apresentar como de resultado, como de mera actividade (ameaças) ${ }^{11}$, sendo que, neste último caso, o crime não poderá ser cometido na modalidade de omissão imprópria, razão pela qual, em cada caso concreto, se impõe averiguar se esse mesmo crime implicou, ou não, a produção de um resultado, seja ele a efectiva ofensa à saúde enquanto bem jurídico complexo, seja ele a mencionada dimensão de respeito que é ferida pelo mau trato.

Ainda em jeito de intróito para o tema que aqui curamos, importa verificar qual o universo de vítimas e de agentes que poderão integrar o artigo $152 .^{\circ} \mathrm{do}$ Código Penal. Destarte, começaremos por dizer que o amplo leque de vítimas deste crime determina igualmente o vasto leque de autores, começando pelo cônjuge e terminando naquele que coabita com pessoa particularmente indefesa. Dada a sua amplitude, impõe-se que os consideremos divididos em três grandes grupos, a saber: um primeiro, onde se integra o cônjuge, a pessoa do outro ou do mesmo sexo com quem o agente mantém uma relação análoga à dos cônjuges, ainda que sem coabitação; um outro, constituído pela pessoa particularmente indefesa que coabite com o agente e, por fim, um terceiro, constituído pelo ex-cônjuge, pela pessoa do outro ou do mesmo sexo com quem o agente manteve uma relação de namoro ou uma relação análoga à dos cônjuges e pelo progenitor de descendente comum, e pelo agente que mantém uma relação de namoro com a vítima.

Resulta da classificação que acabámos de fazer que o primeiro grupo de possíveis agentes se encontra unido à vítima de forma estável, existindo entre eles ou uma relação de casamento ou uma relação análoga ao casamento.

Quanto ao segundo grupo de casos, correspondente à alínea $d$ ), a sua inserção no elenco de potenciais vítimas de um crime de violência doméstica não deixa de ser estranha, na medida em que tanto aqui cabe um filho menor, ou maior, tanto monta, como um pai, um avô, como uma tia, ou um tio do agente, um estranho, desde que se encontrem em coabitação. Daqui se retira, em primeiro lugar, que se se tratar de filho menor de idade, o presente grupo, a presente alínea não tem sentido, porque o menor, sem se distinguir se é filho, ou não, sempre teria protecção no âmbito do número 2 , alínea $a$ ). Se for o cônjuge,

11 Cf. Paulo Pinto de Albuquerque, Comentário do Código Penal Português, 593. No mesmo sentido, cf. Taipa de Carvalho, "Art. 152.”", 520. 
a mesma também não se justifica, pois o mesmo tem tratamento autónomo e próprio em sede da alínea a) do número 1 . Por isso, melhor fora que esta alínea $b$ ) fosse revista, no sentido de aí inserir, por exemplo, os ascendentes e descendentes e irmãos e, depois, se construísse a alínea de forma a colocar, dentro do seu âmbito, relações substancialmente análogas às de ascendentes e descendentes.

Já quanto ao último grupo que acima identificámos, na verdade, cremos que não faz sentido estar aqui incluído, porque, recordemo-lo uma vez mais, estamos perante um crime que se pressupõe praticado num contexto doméstico, de relação familiar, que, no caso, já não existe, já pertence ao passado. Ora, quanto a estes, sem pretendermos repetir a estranheza que estes causam não só na qualificação do homicídio ${ }^{12}$, como também em sede deste crime, pensamos que eles simplesmente não deveriam aqui ter inclusão. Claro que, bem sabemos, a Convenção do Conselho da Europa para a Prevenção e o Combate à Violência contra as Mulheres e a Violência Doméstica (Convenção de Istambul) dispõe, no seu artigo $3 .^{\circ}$, que a violência doméstica pode ser cometida dentro da família, na unidade doméstica, ou entre cônjuges ou ex-cônjuges, ou entre companheiros ou ex-companheiros, quer o agente coabite ou tenha coabitado ou não com a vítima ${ }^{13}$. Por fim, temos para nós que os crimes cometidos em família ou em instituições análogas não se deve estender à relação de namoro, nem a relações passadas, nem mui menos a progenitor de descendentes comuns. Quando muito, a relação de namoro

12 Cf. Alexandra Vilela, «A propósito da técnica de qualificação do homicídio prevista no artigo 132. ${ }^{\circ}$ do Código Penal (As suas alterações legislativas e a sua aplicação), in: Revista da Faculdade de Direito e Ciência Politica, n. ${ }^{\circ} 11$, Nova Série, (2018): 124-126.

13 Cf. Teresa Morais, Violência doméstica (o reconhecimento jurídico da vítima), (Reimpressão, Coimbra: Almedina, 2020), 24-26. Face ao que em texto escrevemos, embora compreendamos a evidência de que o legislador de 2007 tentou "uniformizar o circulo das vitimas que beneficiam da tutela reforçada dos crimes de homicídio qualificado, de ofensas à integridade física qualificada e de violência doméstica", não acompanhamos Nuno Brandão quando afirma que ela conduz a uma tutela penal especial, fundada no vinculo familiar presente ou passado que as ligue ao agente. Cf., do autor, "A tutela penal", 10. Na verdade, como já tivemos oportunidade de referir, a preocupação de o legislador do CP ao pretender que não se abram brechas na protecção oferecida às vítimas em sede de homicídio qualificado, de acordo com a alínea b) do número 2 do artigo $132 .^{\circ}$, bem como em sede de violência doméstica, conduziu-o a uma solução que parecendo exaustiva, por vezes, perde o sentido (veja-se, por exemplo, o facto de o homicídio "contra progenitor de descendente comum em $1 .^{\circ}$ grau") e, outras, pode revelar-se redutor, fruto da ausência da técnica dos exemplos-padrão, em sede do crime de violência doméstica. Neste enfiamento, leia-se o que escrevemos em "A propósito do designado 'Direito Penal da Família”, 64 e seguinte, bem como em "Notas sobre a última revisão ao Código Penal: um exemplo, o artigo 132. ${ }^{\circ}$, in: RPCC, $n .^{\circ} 2,2009,211$ e seguinte. 
poderia aqui merecer um tratamento de relação substancialmente análoga à conjugal.

Mais uma vez, por aqui se demonstra que a indicação das vítimas de violência doméstica deveria ser exemplificativa, abrindo assim espaço a que pudessem ser vítimas aqueloutras cuja situação fosse substancialmente análoga à dos pais e dos filhos.

\section{O CRIME DE VIOLÊNCIA DOMÉSTICA COMETIDO SOB A FORMA OMISSIVA}

Como sabemos, o crime cometido sob a forma de omissão impura deverá ser de resultado, dependendo a sua incriminação "de um jogo que envolve a interação entre as normas subjacentes aos específicos tipos delitivos da $\mathrm{PE}$ e uma norma de extensão", qual seja a do artigo $10 .^{\circ}$. Com efeito, aí encontramos o pressuposto da admissibilidade do funcionamento da cláusula de equiparação da omissão à acção e que se traduz no facto de o agente omitente se encontrar investido de um dever de evitar a produção de resultados penalmente relevantes. Mais acresce que a acção omitida pelo agente seja adequada a evitar o resultado e que ele, agente, tenha capacidade para cumprir com a conduta descrita no crime de resultado e não a leve a cabo ${ }^{14}$.

Tendo presente o artigo $152 .^{\circ}$ do CP e para os efeitos do artigo $10 .^{\circ}$, o resultado que aqui releva é o mau trato que coloca em causa o respeito pela vítima. Ora, do que se trata aqui é que o mau trato não é dado de forma activa, pela forma de fazer, mas surge justamente, porque o agente, investido do dever de garante, não levou a cabo a acção adequada a evitar a produção do resultado. Logo, a omissão será causal do resultado, neste caso, os maus-tratos, quando seja legítima a conclusão de que a realização da conduta omitida, em alternativa à omissão, teria impedido a ocorrência desse mesmo resultado.

Dito isto, vejamos, agora, as possibilidades de cada um dos grupos dos agentes atrás identificados ser titular de um dever de garante: no que se refere ao primeiro grupo de vítimas, onde se integra o cônjuge, a pessoa do outro

14 Cf. Faria Costa, Direito Penal, (Lisboa, Imprensa Nacional Casa da Moeda, 2018), 491-492. 
ou do mesmo sexo com quem o agente mantém uma relação análoga à dos cônjuges, ainda que sem coabitação, parece encontrar-se unido à vítima de forma estável, existindo entre eles ou uma relação de casamento ou uma relação análoga ao casamento. Por essa razão, a priori, pensamos poder afirmar que existe um dever jurídico de garante que provém, de acordo com a doutrina da proximidade existencial, do dever de protecção, mais precisamente por nos encontrarmos perante pessoas unidas por um vínculo familiar ou a este análogo. Afinal, o casamento é, ainda, e também, uma fonte de relações familiares.

Por sua vez, no que se refere ao segundo grupo, se é certo que ali se podem incluir os descendentes e os ascendentes, e até irmãos e tios, também é correcto afirmarmos que até um estranho se pode ali integrar. Se assim é, não há grande dificuldade em conceber que o agente se encontre investido de um dever de garante, fruto do dever de protecção existente entre pessoas unidas por laços familiares ou a estes análogos. Mas, a um estranho, como fazer impender sobre ele um dever de garantia de não produção de maus-tratos? De outra maneira: qual a fonte do dever de evitar a produção de um resultado neste caso concreto? Dir-se-ia, considerando a doutrina da proximidade existencial, que seria o dever de vigilância, em virtude de o agente se encontrar em situação de monopólio de facto, em posição de ingerência ou por causa de ter assumido, por contrato, ou de facto, esse mesmo dever de vigilância.

A este propósito, vale a pena vermos o que se passou no âmbito do Acórdão do Tribunal da Relação do Porto de 12 de Junho de 2016 (Processo n. $\left.{ }^{\circ} 2255 / 15.7 T 9 P R T . P 1\right)^{15}$ : no mesmo caso, e relativamente a duas vítimas que coabitavam com o arguido, o tribunal decide de forma diferente: assim, relativamente ao pai do arguido, com quem ele coabitava, decide pela existência de um crime de violência doméstica cometido por omissão, "traduzida na não prestação dos cuidados necessários de que a vítima carece e que leva à verificação do resultado típico: infligir maus-tratos" ${ }^{\prime 6}$. Por sua vez, no que diz respeito à sua tia, a outra vítima, que igualmente vivia com o agente e com o pai deste, e provado que também ela carecia de cuidados alimentares e de higiene, o agente foi absolvido por se entender que "na relação sobrinho/tia

15 Consultável em www.dgsi.pt.

16 As palavras entre aspas correspondem ao Sumário do Acórdão acima referido, no seu ponto I. 
não existe dever jurídico de garante; no caso dos autos, também não existe um dever contratual de assistência, nem uma situação de ingerência [apesar de viverem na mesma casa, o sobrinho não assumiu uma posição de controlo nem existe uma real dependência que leve a tia a apoiar-se nele para a satisfação das suas necessidades (posições de dependência)] — pelo que, quanto a ela, a conduta do arguido é atipica"17.

Dito isto e se já temos dificuldades de enxergar em abstracto a prática do crime de violência doméstica sob a forma omissiva, relativamente a este grupo de pessoas que acima identificámos, muito maior é a contrariedade no terceiro grupo de pessoas que já se encontram desligadas de relações familiares.

Aqui chegados, vejamos agora um outro pressuposto da admissibilidade do funcionamento da cláusula de equiparação da omissão à acção, contida no número 2 do artigo $10 .^{\circ}$ do CP: a acção omitida pelo agente deve ser adequada a evitar o resultado, sem esquecer que o resultado é o mau trato que coloca em causa o respeito pela vítima. Ora, do que se trata aqui é que o mau trato não é dado de forma activa, pela forma de fazer, mas surge, justamente, porque o agente não levou a cabo a acção adequada a evitar a produção do resultado. Como bem assinala Faria Costa, em sede de omissão impura, "uma omissão será causal para o resultado descrito no tipo legal de crime quando se puder concluir que a realização alternativa (contra-fática) da ação esperada (devida) teria impedido a sua ocorrência" ${ }^{18}$, razões, pois, mais do que suficientes para que as cautelas na imputação do resultado cometido a título omissivo ao agente sejam maiores ainda do que na conduta comissiva.

Dito isto, e dado que está em causa uma acção omitida que evitaria os maus-tratos, temos para nós que o leque de casos em que poderão surgir com mais pertinência um crime de violência doméstica serão sobretudo os casos em que o dever de garante emerge ou da lei ou do dever de protecção que surge entre pessoas vinculadas por elos familiares ou relações análogas. Na verdade, há a considerar, ainda com Faria Costa, que aqui acompanhamos de perto, que um "ponto essencial, no quadro das situações de ingerência, comunidade de vida, comunidade de perigo e monopólio de

17 Cf., de novo, o citado Acórdão, no ponto III, do seu Sumário.

18 Cf. Faria Costa, Direito Penal, 508. 
facto mora (...), na presença física do omitente na situação desencadeadora do resultado desvalioso. Se o dever jurídico emergir da lei e do contrato [e acrescentamos nós, se o vínculo for análogo ao protegido por lei] podemos conceber que o omitente não esteja fisicamente presente no momento em que se desencadeia o resultado proibido e, nem por isso, ele deve ver excluída a sua responsabilidade" ${ }^{19}$.

Tudo, enfim, razões que nos levam a afunilar cada vez mais as hipóteses de comissão do crime de violência doméstica sob a forma de omissão, na medida em que a principal e quase esgotante causa de dever de garante é aquela que acima referimos, deixando assim cair as situações de ingerência (o dever surge em virtude de o agente ter criado uma situação de perigo para bens penalmente relevantes de terceiro e, nessa sequência, ter a obrigação jurídica de praticar "aquela" acção adequada a impedir a realização do resultado, o que ele não faz) e as situações de monopólio de facto.

Em síntese conclusiva: entendemos que o círculo de condutas omissivas é reduzido, sendo que o caso mais frequente será o da falta de prestação de cuidados e falta de assistência, quando o omitente tem um dever de evitar a produção do resultado por força de um dever de protecção que surge dada a existência de vínculos familiares ou vínculos a estes análogos.

Julgamos não poder terminar este ponto sem tecermos um brevíssimo comentário quanto à possibilidade de o dever de garantir a não produção de um resultado compreendido no crime de violência doméstica nascer na esfera jurídica de um terceiro. Como acima deixámos expresso, concordamos com Faria Costa quanto à necessidade de o titular do dever de garante (o omitente) se encontrar fisicamente presente, quando surge a situação que desencadeia o seu dever de agir, nos casos de ingerência, de comunidade de vida, de perigo e de monopólio. Por assim ser, em uma primeira análise, parece-nos serem igualmente restritas as hipóteses de um terceiro praticar o crime em apreço sob a forma de omissão, tirante, obviamente, alguns casos, em que o dever de garante surge ou da lei ou do contrato. Poderá, ainda, vir a cometer o crime omissivo de violência doméstica o terceiro que se encontre em situação de monopólio de facto e junto da situação de perigo e que não evite a produção do mau trato tipicamente relevante para o

19 Ibidem, 506. 
crime em apreço. Todavia, mais uma vez, pendemos para considerar que tais hipóteses serão restritas, na medida em que, como sabemos, o crime de violência doméstica é essencialmente cometido da porta de casa para dentro e não raro sem a presença de terceiros que possam assumir qualquer dever de garante.

Aqui chegados, vejamos, agora, a possibilidade de o crime de violência entrar em concurso efectivo com o de omissão de auxílio para assim fecharmos o arco das questões suscitadas pelo título.

\section{RELAÇÕES DE CONCURSO ENTRE O CRIME DE VIOLÊNCIA DOMÉS- TICA E O CRIME DE OMISSÃo DE AUXílLIO}

A previsão do tipo legal de crime de omissão de auxílio contempla dois diferentes tipos: o do número 1 , um tipo legal de crime comum, e o do número 2, um crime específico, na medida em que o agente desta modalidade de conduta é o causador do estado "de grave necessidade" para a vida, para a integridade física ou para a liberdade da vítima.

Deste modo, consideramos que assiste razão a Paulo Pinto de Albuquerque, ao deixar vincado que, nesta modalidade de conduta, o crime de auxílio qualificado é um crime de perigo concreto, na exacta medida em que este foi causado pelo próprio agente ${ }^{20}$. Ora, por assim ser, a nossa atenção centrar-se-á apenas no número 2.

O crime de omissão de auxílio é um crime em que o agente se encontra obrigado a prestar ajuda à vítima, sempre que essa ajuda - aqui entendida em sentido amplo - possa ser prestada por aquele e desde que se encontrem em situação de "grave necessidade" os seguintes bens jurídicos: a vida, a integridade física e a liberdade. No fundo, o tipo objectivo de omissão qualificada tem como elementos não apenas o facto de o agente, aqui omitente, não cumprir com o seu dever de prestar auxílio à vítima, mas igualmente o facto de a "criação de uma situação de perigo" ser da autoria dele, agente.

Decorre do exposto que é irrelevante, para efeitos de preenchimento do tipo legal de crime, que a vítima morra por falta de assistência, ou que,

20 Cf. Paulo Pinto de Albuquerque, Comentário do Código Penal, 782. 
ao invés, ela sobreviva, bem como é indiferente se a integridade física vem efectivamente a sofrer uma lesão, seja ela de monta ou não. O que importa, enfim, é que o agente, depois de ter criado a situação de perigo para os bens jurídicos da vítima identificados na norma, não cumpra o dever especial de auxílio ${ }^{21}$.

Diga-se, em acrescento do que vai dito, que não enxergamos razão para divergirmos de Figueiredo Dias, para quem este dever geral de auxílio só surge quando não se verifiquem os pressupostos do dever geral de garante resultantes de uma situação de ingerência. Portanto, a relação entre o dever geral de auxílio e a do dever de garante é de concurso aparente, legal ou impuro, que se resolve de acordo com as regras da subsidiariedade, sendo o primeiro afastado quando se preencham os pressupostos do segundo ${ }^{22}$.

Ora, de acordo com o percurso que encetamos, e partindo do princípio que já se encontra afastada a prática do crime de violência doméstica sob a forma de omissão, ensaiemos agora a análise desse crime, na forma comissiva, em concurso efectivo com o crime de omissão de auxílio previsto no número 2 do artigo $200 .^{\circ}$ do CP.

A este propósito, diz-nos Paulo Pinto de Albuquerque que, no caso de um crime de ofensas à integridade física, provocada por um atropelamento, revela-se necessário distinguir se o acidente se deve a infracção dolosa ou negligente das regras estradais, da parte do agente. Se assim for, ele coloca-se em posição de garante (pensamos nós, gerado a partir de uma situação de ingerência); mas, se o acidente se deve a um factor aleatório, o condutor não tem um dever de garante; tem apenas um dever especial de auxílio, previsto no número 2 do artigo $200.0^{23}$.

Não cremos, todavia, que seja possível importar este raciocínio para o específico caso da violência doméstica. Na verdade, não vemos que seja viável condenar um agente pelo crime de omissão de auxílio que, depois de sovar dolosamente o seu cônjuge, tal como vinha fazendo ao longo dos

\section{Ibidem, 783.}

22 Ibidem.

23 Neste sentido, cf. Paulo Pinto de Albuquerque, Comentário do Código Penal, 784, a propósito de um atropelamento de um peão em que o condutor pratica uma infracção com dolo ou com negligência. 
últimos três anos, o abandona, inanimado no chão, saindo para a rua, a fim de dar um passeio. Não há dúvidas de que, à face do artigo $152 .^{\circ}$ do $\mathrm{CP}$, este agente cometeu o crime de violência doméstica, na forma comissiva, pois que agrediu o seu cônjuge, entregando-o, depois, à sua sorte, sem providenciar pela sua assistência. Mas o crime de omissão de auxílio, previsto no número 2 do artigo $200 .^{\circ}$, a nosso ver, não pode ser imputado ao agente, pois que ele não representou, nem sequer a título de dolo eventual, que sobre ele impendia o dever de auxiliar a sua mulher. Na verdade, saiu de casa acto contínuo, não tendo nascido nele o dolo de violar o dever geral de auxílio. Aliás, se bem vemos o problema, o agente do crime de violência doméstica, quando comete este crime na forma de acção, encerra em si igualmente o dolo de violar o dever geral de auxílio, razão pela qual não lhe surge dolo relativamente à comissão do crime de omissão de auxílio, sendo, por isso mesmo, afastado pelo facto de nos encontrarmos perante um concurso aparente, legal ou impuro, que deverá ser resolvido de acordo com a regra da consumpção.

Mais uma nota no sentido de não haver concurso efectivo: mandam os cânones interpretativos das normas incriminatórias que partamos do "textonorma", isto é, do texto da lei, para alcançarmos a "norma-texto", o seu "significado intrínseco da norma” o seu âmbito de protecção ${ }^{24}$. E, aqui, certamente que o âmbito de protecção do número 2 do artigo $200{ }^{\circ}$ não foi pensado para concorrer efectivamente com o de violência doméstica, justamente porque no crime de violência doméstica há o dolo de maltratar a vítima e de a deixar entregue à sua sorte, o que faz com que a omissão de auxílio não possa ser convocada para este caso concreto.

\section{Conclusã̃o}

Consideramos, em jeito de balanço final, que o crime de violência doméstica por omissão afasta o crime de omissão de auxílio e que este último não tem espaço quando praticado imediatamente a seguir ao de violência doméstica na forma comissiva.

24 Cf. Faria Costa, Direito Penal, 155-157. 
Todavia, é bom que tenhamos igualmente presente que, para todos os efeitos, existe ainda um crime de violência doméstica agravado pelo resultado, seja pela ofensa à integridade física grave, seja pela morte, nos termos das duas alíneas do número 3 do artigo $152 .^{\circ}$ do CP. 